\title{
Exploring the efficiency potential for an active magnetic regenerator
}

\author{
Eriksen, Dan; Engelbrecht, Kurt; Haffenden Bahl, Christian Robert; Bjørk, Rasmus
}

Published in:

Science and Technology for the Built Environment

Link to article, DOI:

10.1080/23744731.2016.1173495

Publication date:

2016

Document Version

Peer reviewed version

Link back to DTU Orbit

Citation (APA):

Eriksen, D., Engelbrecht, K., Haffenden Bahl, C. R., \& Bjørk, R. (2016). Exploring the efficiency potential for an active magnetic regenerator. Science and Technology for the Built Environment, 22(5), 527-533.

https://doi.org/10.1080/23744731.2016.1173495

\section{General rights}

Copyright and moral rights for the publications made accessible in the public portal are retained by the authors and/or other copyright owners and it is a condition of accessing publications that users recognise and abide by the legal requirements associated with these rights.

- Users may download and print one copy of any publication from the public portal for the purpose of private study or research.

- You may not further distribute the material or use it for any profit-making activity or commercial gain

- You may freely distribute the URL identifying the publication in the public portal 


\section{Exploring the efficiency potential for an active magnetic regenerator}

A novel rotary state of the art active magnetic regenerator (AMR) refrigeration prototype was used in an experimental investigation with special focus on efficiency. Based on an applied cooling load, measured shaft power and pumping power applied to the AMR, a maximum second-law efficiency of $18 \%$ was obtained at a cooling load of $81.5 \mathrm{~W}$, resulting in a temperature span of $15.5 \mathrm{~K}$ and a COP of 3.6. A loss analysis is given, based on measured pumping power and shaft power together with theoretically estimated regenerator presssure drop. It is shown that, especially for the pressure drop, significant improvements can be made to the machine. However, a large part of the losses may be attributed to regenerator irreversibilities. Considering these unchanged, an estimated upper limit to the $2^{\text {nd }}$-law efficiency of $30 \%$ is given by eliminating parasitic losses and replacing the packed spheres with a theoretical parallel plate regenerator. Furthermore, significant potential efficiency improvements through optimized regenerator geometries are estimated and discussed.

\section{Introduction}

Magnetic refrigeration is a promising emerging alternative to conventional vapor compression refrigeration. It is based on magnetization and subsequent demagnetization of a magnetocaloric material (MCM), which thereby heats up and cools down. By means of a heat transfer fluid, excess heat may be rejected to the surroundings and a cooling load accepted from a cold reservoir in what is known as the active magnetic regenerator (AMR) cycle (Kitanowski et al. 2015). As the refrigerant is a solid state material and the heat transfer fluid may be a water based liquid, hazardous and environmentally harmful gases are avoided. The absence of a compressor opens the possibility for a more silent operation. However, the main argument in favor of magnetic refrigeration is the potential for high efficiency. Already in 1998, COPs above 6 were demonstrated (Zimm et al. 1998). This was, however, obtained with a superconducting magnet producing a magnetic field of $5 \mathrm{~T}$ and the power consumption of this was not included in the $C O P$, which was furthermore adjusted to ignore seal friction. Since then, an increasing number of AMR prototypes based on permanent magnets have been reported by various groups (Bjørk et al. 2010, 
Kitanowski et al. 2015). Besides this, numerical AMR modelling has indicated the possibility of obtaining competitive COPs (Engelbrecht et al. 2006, Engelbrecht 2008). However, technological and scientific challenges, spanning from development and basic understanding of the MCMs themselves to actual machine design issues, have made the road towards the ultimate goal of a magnetic refrigerator with a competitive $C O P$ long and bumpy - and we are not quite there yet. This is reflected in the fact that only a few of the groups presenting prototypes have even reported $C O P$ s - the focus has in general been more on obtaining relevant temperature spans and cooling powers. A group at the Tokyo Institute of Technology and Chubu Electric Power Co. presented a rotary AMR device in 2005 (Okamura et al. 2005) and further development by this group has resulted in an prototype with a $C O P$ of 2.5 at a temperature span of $5 \mathrm{~K}$ (Okamura and Hirano 2013). Astronautics Corporation of America has recently presented results from a prototype operating at a $C O P$ above 2 at a temperature span of $10 \mathrm{~K}$ (Jacobs et al. 2014). Pushing the development towards more efficient devices makes it crucial to obtain knowledge about issues limiting the performance to reveal opportunities of improved future designs. At the Technical University of Denmark, a thorough loss analysis of a rotary prototype (Lozano et al. 2013) has revealed a number of significant design issues reducing $C O P$, the most important being friction in the flow system and heat leaks. This knowledge has been used in the design of a recently published novel prototype (Eriksen et al. 2015a) in which the flow is controlled by poppet valves giving greatly reduced friction. Furthermore, special care has been taken to minimize heat leaks by keeping components compact and well insulated on the cold side and by including an insulating air gap between regenerator and magnet (Eriksen et al. 2015a). In the present paper, the most recent results obtained with this device are presented. Furthermore, the work input to the AMR is analyzed in order to map out the different losses, both relating to the pumping power and drive power. Based on this, possibilities for future improvements are discussed. 


\section{Experimental setup}

The presented study was carried out on a recently constructed AMR prototype at the Technical University of Denmark (Eriksen et al. 2015a). The setup is illustrated in Figure 1. A cylindrical regenerator is divided into eleven beds filled with a total of $1.7 \mathrm{~kg}$ of closely packed spheres of $\operatorname{Gd}$ and $\operatorname{Gd}_{(1-\mathrm{x})} \mathrm{Y}_{\mathrm{x}}$. The diameter of the spheres is between $500 \mu \mathrm{m}$ and $600 \mu \mathrm{m}$ for the Gd spheres while it is between $300 \mu \mathrm{m}$ and $500 \mu \mathrm{m}$ for the alloys. The beds are subsequently magnetized and demagnetized by a rotating Halbach-like magnet arrangement which is supported on the outside by three HEPCO bearings. On top of the rotating magnet, two cam rings actuate poppet valves controlling the flow in each direction in the beds, timed with the varying magnetic field. The rotating part is driven by a motor with a gear box. The rotational speed of the shaft is measured by an optical encoder. On the drive shaft, between gear box and driving gear, a torque transducer is installed. On the cold side of the regenerator, a compact manifold comprising a system of check valves ensures a unidirectional flow through an insulated electrical heater, in which a controlled heat load can be applied. The temperature on the hot side is controlled by a temperature controlled bath (not shown) connected to the hot heat exchanger. The flow is driven by a gear pump. For further details regarding the machine design, see Eriksen et al. 2015a. Temperatures are measured on both the hot and cold side of the AMR by thermocouples, pressure is measured by pressure gauges, and the fluid flow rate is measured by an in-line flow meter as indicated in Figure 1.

\section{Analysis}

In the present investigation the AMR performance is characterized by considering the shaft work and pumping power as inputs to the system consisting of magnet, regenerator and flow control components, indicated as "AMR machine" in Figure 1. The pumping power, $\dot{W}_{\text {pump }}$, is evaluated as the total pressure drop over the AMR machine times the volumetric flow rate, whereas the shaft power, $\dot{W}_{\text {shaft }}$, is calculated as

$$
\dot{W}_{\text {shaft }}=2 \pi \times \tau \times f_{\text {rot }}
$$

where

$\tau=$ torque 
$f_{\text {rot }}=$ rotational frequency

When a certain cooling load, $\dot{Q}_{\mathrm{C}}$, is applied via the electric heater during an AMR experiment, the COP at steady state may be evaluated as

$$
C O P=\dot{Q}_{\mathrm{C}} /\left(\dot{W}_{\text {pump }}+\dot{W}_{\text {shaft }}\right)
$$

In the present analysis we consider the temperature span, $\Delta T$, to be the temperature difference between the time averaged temperatures exiting the regenerator at the hot end $\left(T_{\mathrm{C}}\right)$ and cold ends $\left(T_{\mathrm{H}}\right)$. However, to calculate a $2^{\text {nd }}$-law efficiency, we will use the temperatures entering the hot side $\left(T_{\mathrm{H}, \text { in }}\right)$ and cold side $\left(T_{\mathrm{C}, \text { in }}\right)$ of the AMR machine as this would resemble the reservoir temperatures of a corresponding Carnot machine:

$$
\eta_{2 \mathrm{nd}, \mathrm{AMR}}=C O P / C O P_{\mathrm{Carnot}}=\left(T_{H, \text { in }}-T_{C, \text { in }}\right) / T_{\mathrm{C}, \mathrm{in}} \times C O P
$$

\section{Experimental AMR Results}

A series of AMR experiments were carried out with varying hot side temperatures, but with fixed AMR frequency, $f_{\mathrm{AMR}}$, of $1 \mathrm{~Hz}$, a fluid flow rate of $\dot{V}=2.5 \mathrm{~L} / \mathrm{min}$ and an applied cooling load of $\dot{Q}_{\mathrm{C}}=81.5$ W. The ambient tempeature was $293 \mathrm{~K} \pm 1 \mathrm{~K}$ during the tests. In each experiment, experimental values were recorded once steady state was reached. This was obtained once the average temperatures in and out of the AMR machine were unchanged for several minutes. The resulting temperature spans and COPs are shown in Figure 2 (a). A maximum temperature span of $\Delta T=16.7 \mathrm{~K}$ was achieved at a hot side temperature of $19.5^{\circ} \mathrm{C}$. By keeping the hot side temperature fixed, a second series of experiments was conducted by varying the AMR frequency and keeping everything else unchanged. The results are shown in Figure 2 (b). For these experiments, a highest second law efficiency of $\mathrm{y}_{2 \mathrm{nd}, \mathrm{AMR}}=18 \%$ was achieved at $f_{\mathrm{AMR}}=0.61 \mathrm{~Hz}$. In this case, the temperature span was $15.5 \mathrm{~K}$ and the $C O P$ was 3.6 . The total pumping

power was $\dot{W}_{\text {pump }}=8.9 \mathrm{~W}$ and the shaft power was $\dot{W}_{\text {shaft }}=14 \mathrm{~W}$. An overview of the experimental uncertainties can be found in Table 1.

\section{Loss analysis - what is limiting the efficiency?}


The experiment with $\eta_{2 \mathrm{nd}, \mathrm{AMR}}=18 \%$ at $f_{\mathrm{AMR}}=0.61 \mathrm{~Hz}$ and $\dot{V}=2.5 \mathrm{~L} / \mathrm{min}$ described above will in this section be used as a starting point for a loss analysis to identify the reasons why the actual work is more than five times that of a corresponding Carnot cooling machine, although the magnetocaloric effect is reversible in second order MCMs, like the ones used in the present regenerator.

\section{Mechanical losses}

In order to evaluate losses increasing the necessary mechanical work which is input as shaft power to the AMR machine, experiments were conducted in which the machine was operated without pumping (no AMR cycles) at different rotational speeds. For practical reasons, the regenerator was installed during all of these experiments, which were conducted at room temperature. Previous experiments have shown a very minor influence of the presence of the regenerator on the shaft power under such conditions, and this is neglected here. The resulting measured shaft powers are therefore considered equal to what is dissipated during AMR operation due to drive gear losses and friction in bearings and poppet valve system. These experiments were then repeated without the poppet valves installed. The resulting shaft powers with and without the valves installed are plotted as functions of corresponding AMR frequencies and fitted with power laws as phenomenological models, see Figure 3. The difference between the value of the two functions at a given frequency then corresponds to the power dissipation due to valve friction. In the case of $f_{\mathrm{AMR}}=0.61$, the dissipation due to bearings and gear corresponds to $1.6 \mathrm{~W}$, while the valve friction accounts for $1.1 \mathrm{~W}$.

\section{Pumping losses}

The total measured pressure drop over the AMR machine includes that of the regenerator itself as well as those caused by the flow system components. The flow system components include the poppet valves, needle valves used to normalize flow resistance, the cold manifold, check valves, fittings and connecting tubing. For the packed sphere bed, a theoretical estimate of the pressure drop can be given (Ergun and Orning 1949): 


$$
\Delta P=\left(\left(18 \times \pi^{2} \times(1-\varepsilon) / \mathrm{d}_{\mathrm{sp}}+1.8 \times v_{s} \times \rho_{\mathrm{f}} / \mu_{f}\right) \times v_{s}^{2} \times \rho_{\mathrm{f}} /\left(\varepsilon^{3} \times \mathrm{Re}_{\mathrm{sp}}\right)\right) \times \mathrm{L}
$$

$$
\begin{aligned}
& \text { where } \\
& \varepsilon \quad=\text { porosity } \\
& \mu_{\mathrm{f}}=\text { fluid viscosity } \\
& v_{s}=\text { superficial velocity } \\
& d_{\mathrm{sp}}=\text { sphere diameter } \\
& \rho_{\mathrm{f}} \quad=\text { fluid density } \\
& \mathrm{L} \quad=\text { length of bed }
\end{aligned}
$$

Here, the superficial velocity is defined as

$$
v_{s}=\dot{m} /\left(\rho_{\mathrm{f}} \times \mathrm{A}_{\mathrm{c}}\right)
$$

where

$\dot{m}=$ mass flow rate

$\mathrm{A}_{\mathrm{c}}=$ cross sectional area of the bed

and the Reynolds number is defined as

$$
R e_{s p}=\mathrm{d}_{\mathrm{sp}} \times v_{s} \times \rho_{\mathrm{f}} /\left((1-\varepsilon) \times \mu_{\mathrm{f}}\right)
$$

For the viscosity and density of the fluid, values corresponding to the average regenerator temperature are used. The porosity is set to $\varepsilon=0.36$, corresponding to closely packed spheres. For the sphere diameter, the mean value of $d_{s p}=460 \mu \mathrm{m}$ is used. Apart from minor spikes in the flow profiles (Eriksen et al. 2015b) which are neglected here, three beds are open to flow in both directions in the AMR machine at all times. For the considered AMR experiment, one bed carries one third of the $\dot{V}=2.5 \mathrm{~L} / \mathrm{min}$ which corresponds to a superficial velocity of $3.87 \times 10^{-2} \mathrm{~m} / \mathrm{s}$. From Equation 4 this implies an estimated pressure drop of $\Delta P=$ 0.49 bar through the beds in one direction, corresponding to $\Delta P_{\mathrm{AMR}}=0.98$ bar over the entire $\mathrm{AMR}$ machine (hot to cold and cold to hot). This estimated pressure drop caused by the packed sphere beds yields an estimated pumping power of $\dot{W}_{\text {pump,reg }}=4.1 \mathrm{~W}$. Hence, the pumping power due to external components accounts for an estimated $\dot{W}_{\text {pump,ext. }}=4.8 \mathrm{~W}$.

\section{Distribution of input power to the AMR machine}


The results and estimates given in the above section are summarized in Table 2 and the relative distribution is shown in Figure 4. The 7,2 W, corresponding to $31 \%$ of the input power, which are not accounted for above, are considered regenerator losses. These will inevitably arise from heat leaks, flow bypass or flow channeling, and entropy generation due to axial conduction, dispersion and heat transfer between fluid and solid in the regenerator.

\section{Discussion}

Mapping out the losses as in the case study presented above is crucial to get an insight into which improvements might be done in future designs to maximize efficiency. But furthermore, it may be used to estimate an upper limit for the efficiency that might be reached based on actual experiments rather than (just) modeling.

\section{Machine design}

In the present case, the external HEPCO bearings support the magnet via a steel ring. The dynamical contact between bearings and ring implies not only rolling but also sliding. The associated dissipation due to friction might be greatly reduced by choosing a different bearing design using low friction centralized roller bearings. Mechanical losses from the gear drive and poppet valve friction may also be reduced by design engineering efforts. As for the pumping power, a very significant part is consumed by external components. As can be seen from Figure 1, each bed is connected to different valves with systems of bent hoses. The cold manifold is very compact to minimize heat leaks as mentioned, but it also introduces a significant flow resistance. The fluid flows through two check valves, each with a crack pressure, and associated pressure loss, of 0.07 bar. Again, much of these losses may be avoided by relatively simple design improvements.

\section{Regenerator design}

When it comes to the work required to drive the fluid through the regenerator beds themselves, this might be greatly reduced by going from the packed spheres currently used to parallel plates (Nielsen et al. 2012). Detailed analysis comparing beds of different geometries, including spheres and parallel plates, can 
be found in (Trevizoli 2015). To give an estimate of the potential reduction of the pressure drop in the present case, a parallel plate regenerator with the same heat transfer effectiveness and amount of magnetocaloric material as the current packed sphere regenerator could be considered. This is done in the Appendix. In the present case, this results in a regenerator with a plate thickness of $159 \mu \mathrm{m}$ and a plate spacing of $89.5 \mu \mathrm{m}$. Realizing such a geometry with the relevant MCMs may pose a greater challenge, as even small variations in the plate spacing will greatly reduce the regenerator performance (Nielsen et al. 2012). However, such a regenerator would reduce the pumping power associated with the porous beds from 4.09 $\mathrm{W}$ to $2.24 \mathrm{~W}$ as estimated in the Appendix. To give an estimated upper limit for the achievable efficiency based on the present case, an imaginary corresponding AMR machine could be considered, in which the mechanical losses are eliminated as well as the pressure drop in the external components. Furthermore, the corresponding plate regenerator with perfect stacking and lower pressure drop is considered. For simplicity, the regenerator losses are considered unchanged. This situation would correspond to a second law efficiency of $30 \%$. However, the assumption of unchanged regenerator losses can indeed be questioned. The regenerator losses are not straightforward to quantify and require evaluation through numerical AMR modeling. In literature, detailed treatments of the entropy generation in regenerators are presented along with suggested minimization methods (Trevizoli and Barbosa 2015, Li et al. 2008). In the real system with non-zero pressure drop in the external components, another complication arises from the fact that the regenerator losses are somewhat interlinked with the pumping losses, as heat dissipated in the fluid takes part in the regeneration process.

An ideal version of the current experiment where parasitic losses are disregarded (but regenerator pumping work and regenerator losses are not) would correspond to a second-law efficiency of $26 \%$.

Recently, a study of regenerator geometries based on numerical AMR simulations has been carried out (Lei et al. 2015). The analysis was based on conditions quite similar to those of the experiment considered here and the results may be used to roughly estimate potential improvements of the current experimental efficiency, disregarding parasitic losses due to pressure drop over external components and mechanical losses.

Firstly, the current regenerator shape is a compromise between many design choices including availability of MCM and magnet geometry. Therefore, the combination of hydraulic diameter, $d_{h, s p}=173$ 
$\mu \mathrm{m}$ (see Appendix), and aspect ratio, $\mathrm{R}_{\mathrm{a}}=\mathrm{L} / \sqrt{ } \mathrm{A}_{\mathrm{c}}=4.7$, is not optimal. If the sphere diameter is fixed, reducing the aspect ratio to 3.4 and increasing the frequency to $1.9 \mathrm{~Hz}$ would increase the $C O P$ by approximately $27 \%$ according to the results of the numerical study, due to both reduced pumping power and regenerator losses.

Secondly, if smaller spheres could be used, corresponding to a sphere diameter of $200 \mu \mathrm{m}$, an increase in $C O P$ of approximately $69 \%$ could be achieved. This would require a rather "short and fat" regenerator with an aspect ratio of 0.95 operating at a frequency of $2.3 \mathrm{~Hz}$.

Finally a regenerator geometry different from the packed sphere bed may be considered. If parallel plates are disregarded due to difficulties of manufacturing, a micro-channel matrix might be an option. Based on the results from the considered numerical study, this could increase the COP by approximately $120 \%$.

\section{Potential improvements - summary}

The experimentally achieved second law efficiency of $18 \%$ may be improved in different ways as discussed above. The achievable second-law efficiencies based on the estimated improvements are given in Table 3. Here, the percentwise improvements of the second-law efficiency related to improved regenerator geometry (No. 4-6 in Table 3) that may be achieved according to the considered numerical study, are given with the experimental value, disregarding external pumping power and mechanical losses, as a basis. It should be noted that the values in Table 3 are idealized because they do not include the efficiency of the motor or pump.

\section{Conclusion}

A series of AMR experiments with a rotary AMR prototype with varying hot side temperature and frequency has resulted in temperature spans of more than $16 \mathrm{~K}$ with corresponding $C O P$ s above 3 , based on shaft power and pumping power as work inputs. The cooling power applied in the experiments was $81.5 \mathrm{~W}$. The experiment with the highest $2^{\text {nd }}$-law efficiency, which was $18 \%$, was used as a basis for a loss analysis. From this it is concluded that significant losses due to pressure drop in external components and to a lesser extent dissipation of mechanical work exist and may be reduced in future designs. Further reduction of pressure drop by going from the packed sphere regenerator to a corresponding parallel plate regenerator is 
discussed, but realizing this in practice would be a larger technological challenge. Finally, significant potential efficiency improvements due to alternative regenerator designs are estimated and discussed. 


\section{Appendix: Corresponding parallel plate regenerator}

To give a theoretical estimate of the maximum potential reduction in pressure drop over the regenerator beds and hence pumping power, a parallel plate regenerator with the same size and amount of magnetocaloric material as the packed sphere regenerator is considered. To characterize the effectiveness in terms of heat transfer of a regenerator, the number of transfer units, NTU, is commonly used:

$$
\mathrm{NTU}=\mathrm{Nu} \times \mathrm{k}_{\mathrm{f}} \times \mathrm{a}_{\mathrm{s}} \times \mathrm{A}_{\mathrm{c}} \times \mathrm{L} /\left(\dot{m} \times \mathrm{c}_{\mathrm{f}} \times \mathrm{d}_{\mathrm{h}}\right)
$$

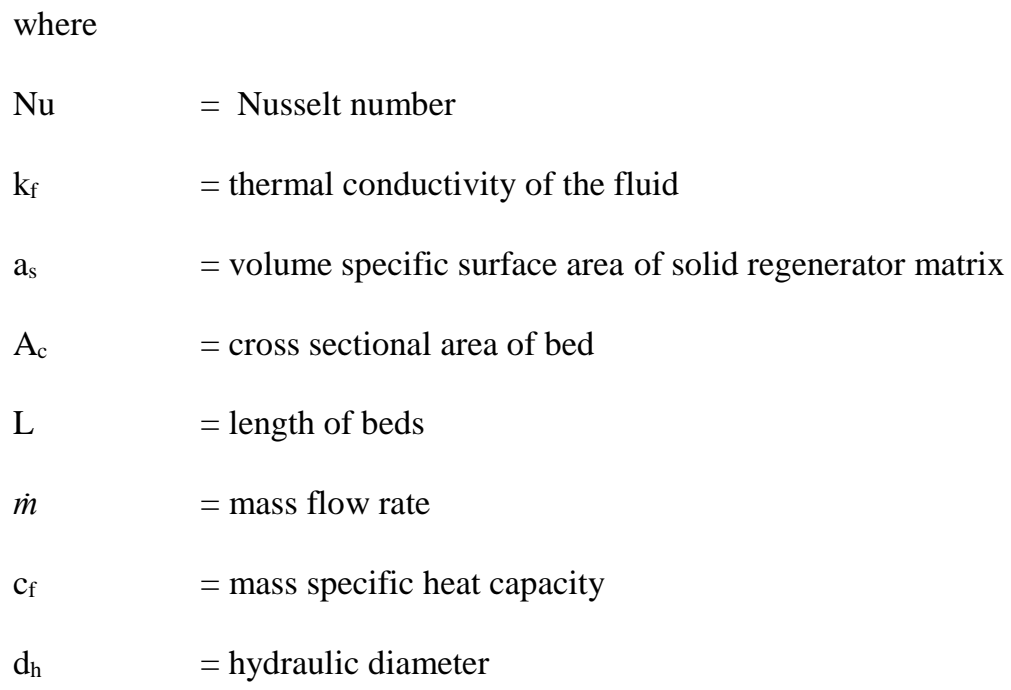

To give a reasonable comparison, this number will be kept the same for the imaginary parallel plate regenerator beds $\left(\mathrm{NTU}_{\mathrm{pl}}\right)$ as it is for the current packed sphere beds $\left(\mathrm{NTU}_{\mathrm{sp}}\right)$. For both the sphere bed and plate bed, the volume specific surface area can be expressed as

$$
\mathrm{a}_{\mathrm{s}}=4 \varepsilon / \mathrm{d}_{\mathrm{h}}
$$

where

$\varepsilon \quad=$ porosity

For the sphere bed, the hydraulic diameter, $\mathrm{d}_{\mathrm{h}, \mathrm{sp}}$, can be expressed in terms of the porosity and sphere diameter:

$$
\mathrm{d}_{\mathrm{h}, \mathrm{sp}}=2 \varepsilon_{\mathrm{sp}} /\left(3 \times\left(1-\varepsilon_{\mathrm{sp}}\right)\right) \times \mathrm{d}_{\mathrm{s}}
$$

where

$\mathrm{d}_{\mathrm{s}} \quad=$ sphere diameter 
$\varepsilon_{\mathrm{sp}} \quad=$ sphere bed porosity

Combining Equations 6-8 yields, for the sphere beds,

$$
\mathrm{NTU}_{\mathrm{sp}}=\mathrm{Nu}_{\mathrm{sp}} \times \mathrm{k}_{\mathrm{f}} \times \mathrm{A}_{\mathrm{c}} \times \mathrm{L} \times 9 \times\left(1-\varepsilon_{\mathrm{sp}}\right)^{2} /\left(\dot{m} \times \mathrm{c}_{\mathrm{f}} \times \varepsilon_{\mathrm{sp}} \times \mathrm{d}_{\mathrm{s}}{ }^{2}\right)
$$

Where

$\mathrm{Nu}_{\mathrm{sp}} \quad=$ Nusselt number for the sphere bed.

For the plate bed, combining Equations 6 and 7 yields

$$
\mathrm{NTU}_{\mathrm{pl}}=\mathrm{Nu}_{\mathrm{pl}} \times \mathrm{k}_{\mathrm{f}} \times \mathrm{A}_{\mathrm{c}} \times \mathrm{L} \times 4 \times \varepsilon_{\mathrm{pl}} /\left(\dot{m} \times \mathrm{c}_{\mathrm{f}} \times \mathrm{d}_{\mathrm{h}, \mathrm{pl}}{ }^{2}\right)
$$

where

$$
\begin{array}{ll}
\mathrm{Nu}_{\mathrm{pl}} & =\text { Nusselt number for the plate bed } \\
\varepsilon_{\mathrm{pl}} & =\text { porosity of the plate bed } \\
\mathrm{d}_{\mathrm{h}, \mathrm{pl}} & =\text { hydraulic diameter for the plate bed }
\end{array}
$$

Besides requiring $\mathrm{NTU}_{\mathrm{pl}}=\mathrm{NTU}_{\mathrm{sp}}$, it is assumed that the amount of $\mathrm{MCM}$ is the same in the two cases, i.e. $\varepsilon_{\mathrm{pl}}=\varepsilon_{\mathrm{sp}}=\varepsilon$. By combining Equations 9 and 10 with these requirements, the hydraulic diameter of the plate bed becomes

$$
\mathrm{d}_{\mathrm{h}, \mathrm{pl}}=2 / 3 \times \varepsilon /(1-\varepsilon) \times \sqrt{ }\left(\mathrm{Nu}_{\mathrm{pl}} / \mathrm{Nu}_{\mathrm{sp}}\right) \times \mathrm{d}_{\mathrm{s}} .
$$

An estimate of the Nusselt number for the sphere bed can be given (Wakao and Kaguei 1982) as

$$
\mathrm{Nu}_{\mathrm{sp}}=2+1.1 \times \operatorname{Pr}^{(1 / 3)} \times \mathrm{Re}^{0.6}
$$

where

$\operatorname{Pr} \quad=c_{\mathrm{f}} \times \mu_{\mathrm{f}} / \mathrm{k}_{\mathrm{f}} \quad=$ Prandtl number

Re $\quad=\dot{m} \times \mathrm{d}_{\mathrm{h}, \mathrm{sp}} /\left(\mathrm{A}_{\mathrm{c}} \times \mu_{\mathrm{f}}\right)=$ Reynolds number

$\mu_{\mathrm{f}} \quad$ =fluid viscosity

For the case of the experiment considered in the loss analysis in the present paper, the Nusselt number from Equation 12 becomes $\mathrm{Nu}_{\mathrm{sp}}=7.96$. For the plate bed, an estimated $\mathrm{Nu}_{\mathrm{pl}}=7.541$ is used, ignoring entrance effects (Nikolay and Martin 2002). By using $\varepsilon=0.36$ (packed spheres) and $\mathrm{d}_{\mathrm{s}}=460 \mu \mathrm{m}$ (average sphere diameter), the hydraulic diameter for the corresponding parallel plate bed, from Equation 11, becomes $\mathrm{d}_{\mathrm{h}, \mathrm{pl}}=179 \mu \mathrm{m}$. This corresponds to a plate spacing of 


$$
\mathrm{S}_{\mathrm{pl}}=1 / 2 \times \mathrm{d}_{\mathrm{h}, \mathrm{pl}}=89.5 \mu \mathrm{m},
$$

and a plate thickness of

$$
\mathrm{t}_{\mathrm{pl}}=\mathrm{s}_{\mathrm{pl}} \times(1 / \varepsilon-1)=159 \mu \mathrm{m} .
$$

For such a parallel plate regenerator, an estimate of the pressure drop may be given (Bejan 1995) as

$$
\Delta P=4 \mathrm{f}_{\mathrm{F}} \times \rho_{\mathrm{f}} \times\left(\mathrm{v}_{\mathrm{s}} / \varepsilon\right)^{2} /\left(2 \mathrm{~d}_{\mathrm{h}, \mathrm{pl}}\right) \times \mathrm{L}
$$

where

$\mathrm{v}_{\mathrm{s}}=$ superficial velocity, see Equation 5

$\mathrm{f}_{\mathrm{F}}=24 / \mathrm{Re}=$ friction factor

Here, the reynolds number is defined as

$$
\operatorname{Re}=\rho_{\mathrm{f}} \times\left(\mathrm{v}_{\mathrm{s}} / \varepsilon\right) \mathrm{d}_{\mathrm{h}, \mathrm{p}} / \mu_{\mathrm{f}}
$$

Based on this, a total pressure drop over the AMR machine in the case of the parallel plate regenerator and the present experiment becomes $\Delta P_{\mathrm{AMR}}=0.538$ bar, corresponding to a pumping power of $\dot{\mathrm{W}}_{\text {pump }}=$ $2.24 \mathrm{~W}$. 


\section{References}

Bejan, A. 1995.Entropy generation minimization: the method of thermodynamic optimization of finite-size systems and finite-time processes. CRC press.

Bjørk, R., Bahl, C.R.H., Smith, A. and Pryds, N. 2010. Review and comparison of magnet designs for magnetic refrigeration. Int. J. Refrig. 33:437-448.

Engelbrecht, K. L., Nellis, G. F. and Klein, S. A. 2006. Predicting the Performance of an Active Magnetic Regenerator Refrigerator Used for Space Cooling and Refrigeration. HVAC\&R Research 12(4):10771095.

Engelbrecht, K. 2008. A Numerical Model of an Active Magnetic Regenerator Refrigerator with Experimental Validation. PhD Thesis, University of Wisconsin - Madison.

Ergun, S. and Orning A. 1949. Fluid flow through randomly packed columns and fluidized beds. Ind. Eng. Chem. 41(6):1179-1184.

Eriksen, D., Engelbrecht, K., Bahl, C.R.H., Bjørk, R., Nielsen, K.K., Insinga, A.R. and Pryds, N. 2015a. Design and experimental tests of a rotary active magnetic regenerator prototype. Int. J. Refrig. 58:1421.

Eriksen, D, Engelbrecht, K., Bahl, C.R.H., Bjørk, R., Nielsen, K.K., Insinga, A., Dallolio, S. and Pryds, N. 2015b. Experimental Studies with an Active Magnetic Regenerating Refrigerator. Proceedings of the $24^{\text {th }}$ IIR Internatona Conference of Refrigeration, Yokohama, Japan.

Jacobs, S., Auringer, J., Boeder, A., Chell, J., Komorowski, L., Leonard, J., Russek, S. and Zimm, C. 2014. The performance of a large-scale rotary magnetic refrigerator. Int. J. Refrig. 37:84-91.

Kitanowski, A., Tusek, J., Tomc, U., Ozbolt, M. and Poredos, A. 2015. Magnetocaloric Energy Conversion From Theory to Application Springer International Publishing.

Lei, T., Engelbrecht, K., Nielsen, K.K. and Veje, C.T. 2015. Study of Geometries of Active Magnetic Regenerators for Room Temperature Magnetocaloric Refrigeration. Appl. Therm. Eng. Accepted manuscript. Available online: http://www.sciencedirect.com/science/article/pii/S1359431115013617

Li, P., Gong, M. and Wu, J. 2008. Geometric optimization of an active magnetic regenerative refrigerator via second-law analysis. J. Appl. Phys 104:103536.

Lozano, J.A., Engelbrecht, K., Bahl, C.R.H., Nielsen, K.K., Eriksen, D., Olsen, U.L., Barbosa Jr., J.R., Smith, A., Prata, A.T. and Pryds, N. 2013. Performance analysis of a rotary active magnetic refrigerator. Appl. Energy 111:669-680.

Nielsen, K.K., Engelbrecht, K., Christensen, D.V., Jensen, J.B., Smith, A. and Bahl, C.R.H. 2012. Degradation of the performance of microchannel heat exchangers due to flow maldistribution. Appl. Therm. Eng. 40:236-247.

Nikolay, M. and Martin, H. 2002. Improved approximation for the Nusselt number for hydrodynamically developed laminar flow between parallel plates. Int. J. Heat Mass Transfer 45(15):3263-3266. 
Okamura, T., Yamadam K., Hirano, N. and Nagaya, S. 2005. Performance of a room-temperature rotary magnetic refrigerator. Proceedings of the $1^{\text {st }}$ International Conference on Magnetic Refrigeration at Room Temperature, Montreux, Switzerland, 319-324.

Okamura, T. and Hirano, N. 2013.Improvement of the performance of room temperature magnetic refrigerator using Gd-alloy. Journal of the Japan Society of Applied Electromagnetics and Mechanics 21(1):10-14.

Trevizoli, P.V. 2015. Development of thermal regenerators for magnetic cooling applications. $\mathrm{PhD}$ Thesis, Federal University of Santa Catarina - Florianopolis, SC.

Trevizoli, P.V. and Barbosa Jr, J.R. 2015. Entropy Generation Minimization analysis of oscillating-flow regenerators. Int. J. Heat Mass Transfer 87:347-358.

Wakao, N. and Kaguei, S. 1982. Heat and Mass Transfer in Packed Beds Gordon and Breach Science Publishers, New York, NY, chapter 8.

Zimm, C., Jastrap, A., Sternberg, A., Pecharsky, V.K., Gschneidner Jr, K.A., Osborne, M. and Anderson, I. 1998. Description and performance of a near-room temperature magnetic refrigerator. Adv. Cryog. Eng. 43:1759-1766. 
Table 1. Measurement uncertainties

\begin{tabular}{cccccc}
\hline Temperature & Pumping power & Flow rate & AMR frequency & Cooling load & Shaft power \\
\hline \hline $0.1 \mathrm{~K}$ & $2 \%$ & $2 \%$ & $0.5 \%$ & $0.05 \%$ & $1 \%$ \\
\hline
\end{tabular}

Table 2. Consumption of power input to the AMR machine, $W$

\begin{tabular}{cccccc}
\hline Carnot work & $\begin{array}{c}\text { Bearings and } \\
\text { gear }\end{array}$ & $\begin{array}{c}\text { Poppet valve } \\
\text { friction }\end{array}$ & $\begin{array}{c}\text { Pumping, } \\
\text { regenerator } \\
\text { beds }\end{array}$ & $\begin{array}{c}\text { Pumping, } \\
\text { external } \\
\text { components }\end{array}$ & $\begin{array}{c}\text { Regenerator } \\
\text { losses }\end{array}$ \\
\hline \hline 4.0 & 1.6 & 1.1 & 4.1 & 4.8 & 7,2 \\
\hline
\end{tabular}

Table 3. Second law efficiency with potential improvements

\begin{tabular}{rcc}
\hline No. & Situation & $\eta_{\text {2nd,AMR, \% }}$ \\
\hline \hline 1 & Current experimental value & 18 \\
2 & As No. 1 without mechanical losses and pumping power due to external & 26 \\
& components & 30 \\
3 & As No.2 with reduced pumping power due to corresponding plate regenerator & 33 \\
4 & As No. 1 without mechanical losses and pumping power due to external & 44 \\
5 & components, regenerator with optimized aspect ratio & 57 \\
6 & As No. 4 with optimized sphere diameter & As No.4 with micro channels \\
\hline
\end{tabular}


Figure 1. Cut away view of AMR machine (left) and schematic flow circuit diagram (right). Sensors measuring temperature, pressure and flow rate are indicated with $\mathrm{T}, \mathrm{P}$ and $\mathrm{F}$ respectively.

Figure 2. AMR results for varied hot side temperature (a) and frequency (b) at an applied cooling load of $81.5 \mathrm{~W}$ and a fluid flow rate of $\dot{V}=2.5 \mathrm{~L} / \mathrm{min}$.

Figure 3. Power dissipation based on measured torque at different frequencies, with and without the poppet valves installed.

Figure 4. Relative distribution of power input to the AMR machine corresponding to experiment with a second law efficiency of $18 \%$. 


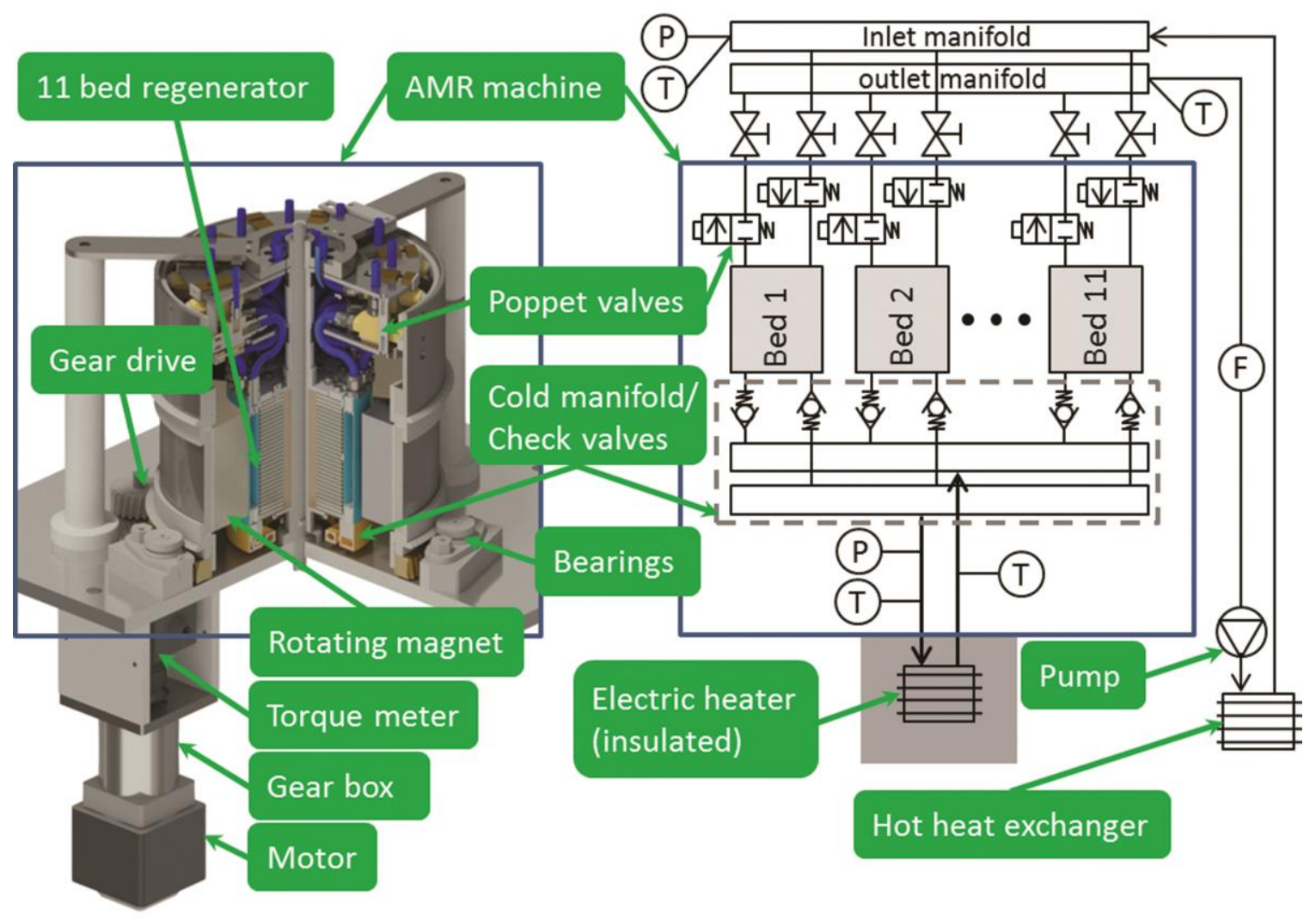

Figure 1
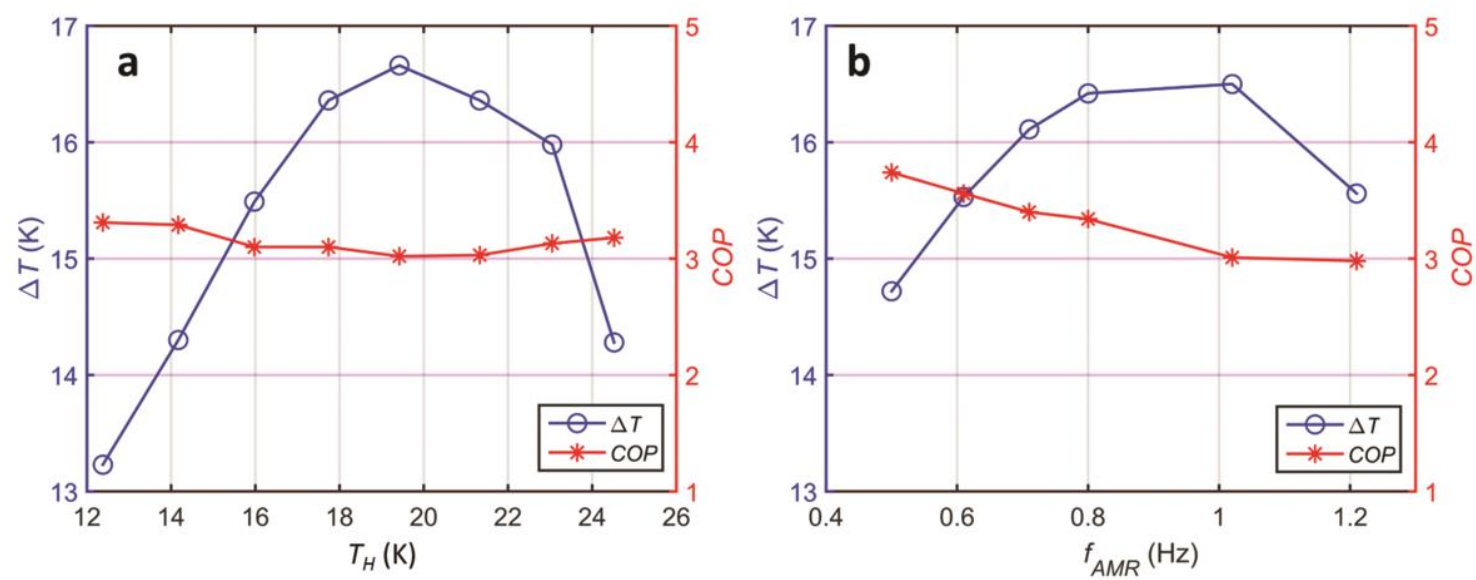

Figure 2 


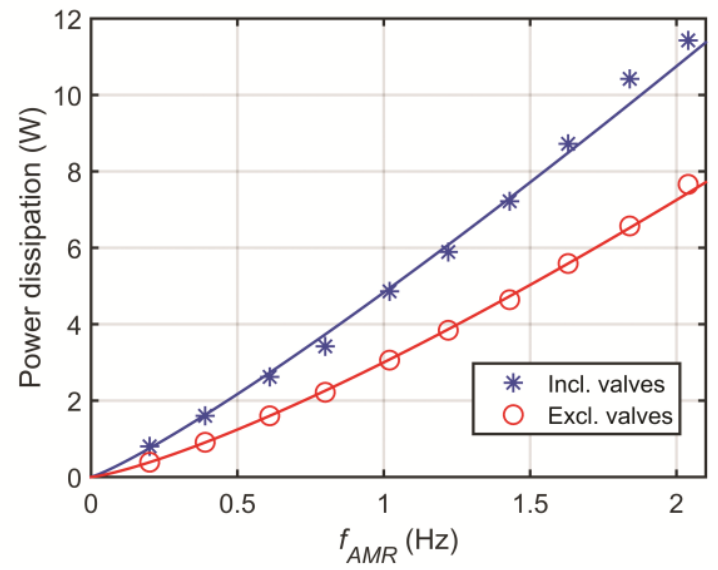

Figure 3

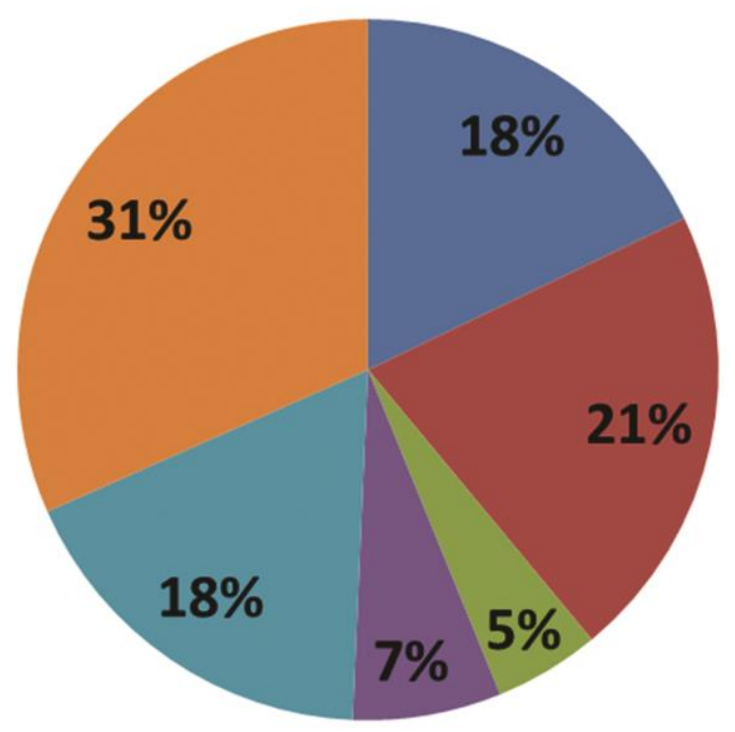

Pumping, regenerator beds

- Pumping, external components

Poppet valve friction

- Bearings and gear

Carnot work

Regenerator losses

Figure 4 